\title{
Wandering Distal End of Ventriculo-Peritoneal Shunt: Our Experience with Five Cases and Review of Literature
}

\author{
Kundal VK' ${ }^{1}$, Gajdhar $M^{2}$, Sharma $C^{3}$, Agrawal D ${ }^{4}$, Kundal R ${ }^{5}$ \\ ${ }^{1}$ Dr. Vijay Kumar Kundal, MBBS, MS, Senior Resident, ${ }^{2}$ Dr. Mufique Gajdhar, MBBS, MS. Senior Resident, ${ }^{3}$ Dr. Chetan \\ Sharma, MBBS, MS, MCH, Professor, ${ }^{4}$ Dr. Deepak Agrawal, MBBS, MS. From the Department of Paediatric Surgery, \\ ${ }^{5}$ Dr. Raksha Kundal, MBBS, MD, Senior Resident, Department of Anaesthesia. All from S M S Medical college and associated \\ SPMCHI, Jaipur, India.
}

Address for correspondence: Dr. VK Kundal, Senior Resident, Department of Paediatric Surgery, S M S Medical college, Jaipur, India. E-mail: vijayraksha@yahoo.com

\begin{abstract}
Ventriculo-peritoneal (VP) shunt is the most commonly performed procedure for the management of hydrocephalus. Although shunts have improved the morbidity and mortality associated with disordered Cerebrospinal fluid (CSF) mechanics over the past 30 years, they still are associated with many potentially avoidable complications in clinical practice. However, extrusion of VP shunt catheter is an unusual complication of VP shunt Surgery. We are presenting this unusual complication in five patients. The lower end of the shunt was seen extruding from anal opening in one patient, umbilicus in one, urethra in one, inguinal hernia sac in one and oral cavity in one patient. All of these patients were managed by shunt removal, intra venous antibiotics followed by shunt replacement on the other side except the patient with inguinal hernia sac.
\end{abstract}

Key words: Ventriculo-peritoneal shunt, Cerebrospinal fluid, Hydrocephalus, Distal end migration, Bowel perforation.

\section{Introduction}

V entriculoperitoneal (VP) Shunt is the classical universally accepted procedure for the treatment of hydrocephalus'. This procedure is associated with various complications. VP Shunt infection, malfunction, pseudocyst, peritoneal contamination and shunt extrusion are common. Shunt malfunction usually associated with infection and poor Cerebrospinal fluid(CSF) drainage, includes the migration of distal end of VP shunt into thoracic cavity ${ }^{2}$, heart ${ }^{3}$, umbilicus ${ }^{4}$, large \& small bowel ${ }^{5}$, urinary bladder $^{6}$, scrotum and inguinal hernia ${ }^{7}$. The reported incidence of shunt related abdominal complications is $10-30 \%{ }^{8}$. Here we are reporting total of five cases with abnormal migration of distal end of VP shunt from anal opening, oral cavity, umbilicus, deep inguinal ring presenting as hernia with hydrocele and urethra.

\section{The Cases}

Case 1: A 7 year old male child admitted with complaints of protrusion of a shunt tube from oral cavity since 4 hours(Fig 1). Ventriculo-peritoneal shunt surgery was done for post-meningitis hydrocephalus one year back in our hospital. Peritoneal end of the shunt tube came out from mouth after patient had an episode of vomiting. Abdominal examination was clinically normal. Child was conscious, hemodynamically stable, had spontaneous eye opening and no neurodeficit. CSF study was normal. USG abdomen was also normal. Distal end of the Shunt was cut and removed from the mouth and rest of the shunt along with reservoir was removed through incision behind the pinna just below the reservoir. Patient was kept nil orally for three days. Orals started on $3^{\text {rd }}$ day and were tolerating oral feeds well. Intravenous antibiotic (I/V) were started and VP shunt was put on other side after 3 days when CSF culture was sterile. Patients were discharged in good general condition without any neurodeficit. Follow up till 18 months was uneventful.

Case 2: A 1 year old male child presented to us with complaints of protrusion of shunt tube through anal opening during passage of stools (Fig 2) and (Fig 3). Patient had right VP shunt surgery done for congenital hydrocephalus 7 months back in our hospital. Clear CSF 
was coming out from tip of extruded shunt tube on pressing the chamber. There were no abdominal signs and symptoms. There was no history of fever, vomiting and no neurological deficit. CSF analysis from ventricular tap was normal but CSF analysis from distal extruded end revealed frank infection. Patient was started on I/V antibiotics and distal end was cut after pulling the shunt tube from anal opening and rest of shunt assembly was removed by incision near the chamber. Patient was kept nil per orally for 3 days and shunt revision was done on left side after 3 weeks when patient developed bulging fontanelle and recurrent vomiting. CT head revealed dilated ventricles. Patient had an uneventful 12 months follow up.

Case 3: A 6 month old male child with a ventriculoperitoneal shunt inserted for congenital hydrocephalus at 1 month of age now presents to us with complaints of protrusion of distal end of shunt through umbilicus(Fig 4). On examination, general clinical findings and neurological examination was within normal limits. Anterior fontanelle was depressed and abdominal examination was also normal. CBC was normal. CSF examination revealed increased WBC (white blood cells), high proteins and low blood sugar. Ultrasonographic (USG) examination was normal. I/V antibiotics were started and whole of shunt was removed from incision near the chamber. Patient was kept nil per orally for 3 days. Shunt revision was done on left side after 3 weeks when CSF culture was sterile. In the meantime patient was managed on mannitol and acetazolamide. 6 month follow up was uneventful in this patient.

Case 4: An 18 month old male child with VP shunt inserted for congenital hydrocephalus at age 8 month now presented to us with complaints of urinary retention and protrusion of white shunt tube through urethral opening. There was no history of fever, vomiting or constipation. Abdominal examination and neurologic examination was normal. CBC was also normal. USG examination of abdomen showed the presence of distal shunt tube in urinary bladder. Under I/V antibiotics cover, shunt tube was removed through incision near chamber and pulled slowly. Cystoscopic examination revealed site of catheter perforation on left side of urinary bladder about 3-4 mm in size. Indwelling Foleys catheter was inserted and kept for 2 weeks. Shunt revision on left side was done after 3 days as the CSF culture was sterile. During follow up for 10 months, there was no complication noted.

Case 5: 2 year old male child with past history of VP shunt inserted at the age of 6 months for congenital hydrocephalus now presented to us with complains of right inguino- scrotal swelling since 1 month. Abdominal examination and neurological examination was normal.
On inguinal exploration shunt tube was seen coming out through deep inguinal ring(Fig 5). On pressing chamber clear CSF was coming out from distal end of shunt tube. Shunt tube was reposited back in peritoneal cavity and inguinal herniotomy was done and hydrocoele fluid was drained. CSF examination was sterile. Patient was followed for 6 months, no uneventful course occured.

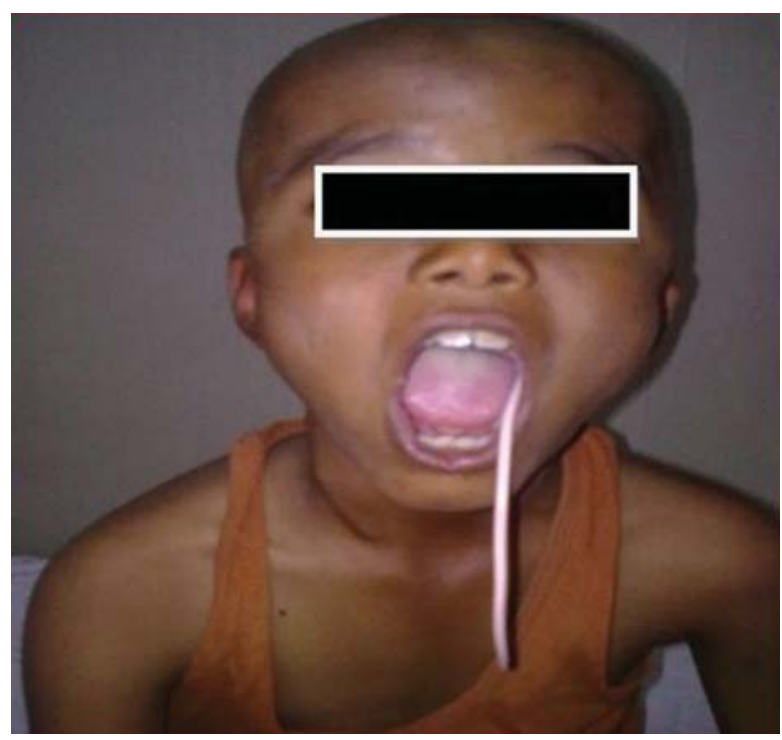

Fig 1: Showing distal end of shunt tube coming out from oral cavity

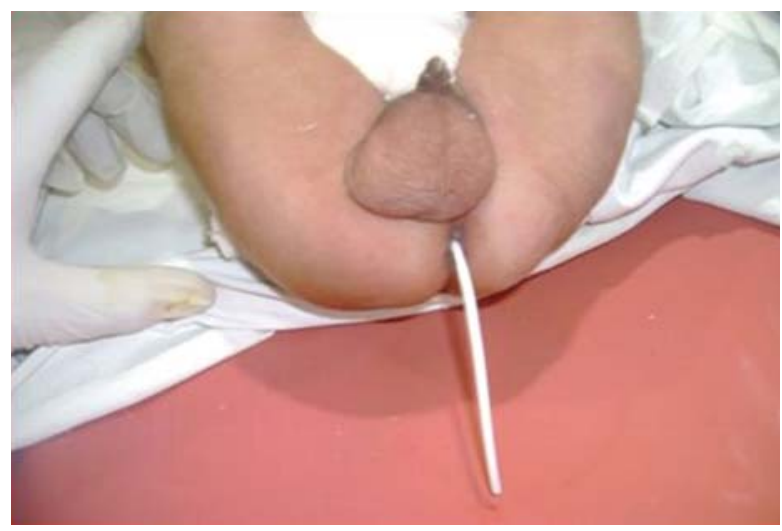

Fig 2: Showing distal end of the shunt tube coming out from anal opening

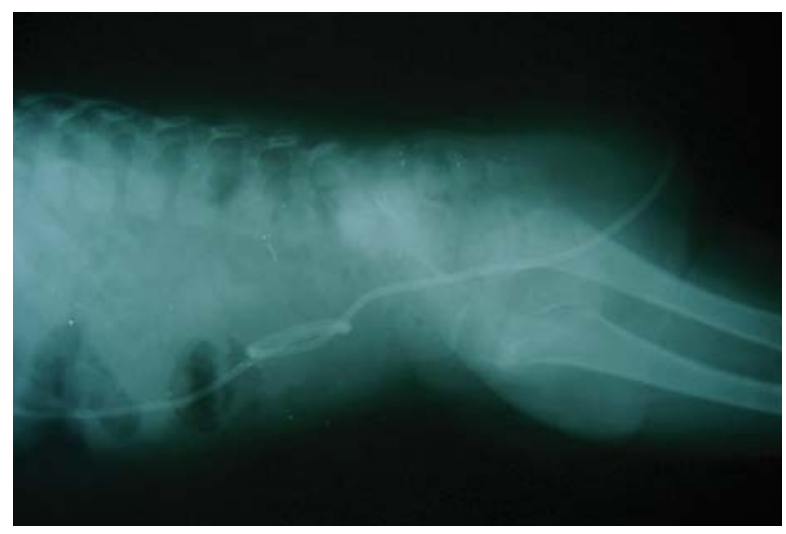

Fig 3: Showing lateral radiograph showing distal shunt tube passing the pelvis 


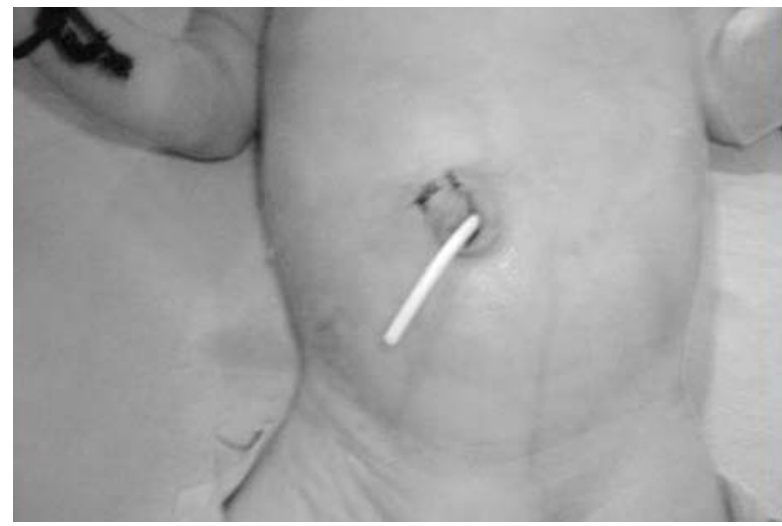

Fig 4: Showing distal end of shunt tube coming out from umbilicus

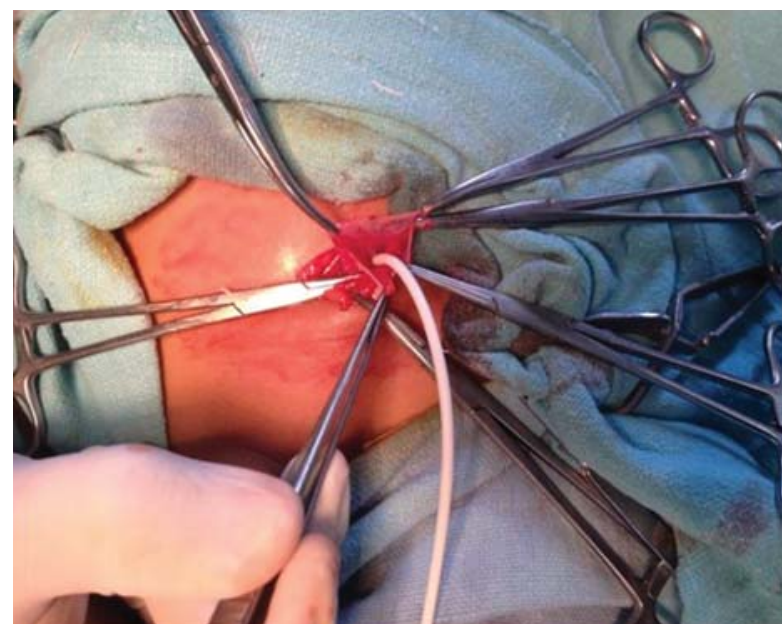

Fig 5: Showing distal shunt tube coming out through deep inguinal ring

\section{Discussion}

Ventriculo-peritoneal shunt, is the most common surgical procedure for treatment of hydrocephalus ${ }^{8}$. Ventriculo-peritoneal shunt diverts the CSF from dilated ventricle to peritoneal cavity, from where CSF is absorbed. However, the complications related to VP Shunt are common and the reported incidence of shunt related abdominal complications is $10-30 \%{ }^{9}$. Bowel perforation and anal extrusion of a distal peritoneal shunt is an unusual complication occurring in less than $0.1 \%-0.7 \%$ of cases $^{10}$. Perforation of nearly every hollow viscus has been reported ${ }^{11}$. These include the stomach, small \& large bowel ${ }^{12,13}$, urinary bladder $^{6}$, vagina \& fallopian tubes ${ }^{14}$ and scrotum ${ }^{15}$ with extrusion of distal shunt tube through rectum.

Perforation of an intra-abdominal hollow viscus by VP shunt is a rare complication associated with $15 \%$ mortality ${ }^{18,19}$. The exact cause of peritoneal catheter perforation into hollow viscus is not known. It could be because of silicon in shunt tube which results in break in continuity of epithelium at contact site. Local inflammation and resulting fibrosis, adherence of distal shunt tube and continous water hammer effect of cerebrospinal fluid pulsations can perforate the bowel wall. Once in bowel lumen, shunt tube is pushed downward and forward by peristaltic waves. Weak innervation of intestinal wall in patients of congenital hydrocephalus and spinal dysraphism also predisposes them to bowel perforation ${ }^{16,17}$. Poor host immunity, surgical technique and long peritoneal tubing also contributes to shunt extrusion. Shunt tube in gastrointestinal lumen for a long time, results in severe ventriculitis, meninigitis, and encephalitis.

The management of these patients of shunt extrusion involves removal of shunt, I/V antibiotics, external CSF drainage, nil per orally and re-insertion of shunt on opposite side or endoscopic third ventriculostomy(ETV). Drugs such as acetazolamide, mannitol may be given temporally after shunt removal to control CSF production. After removal of shunt tube, bowel perforation heals spontaneously due to presence of chronic fibrous sheath around shunt track. Emergency laparotomy is needed only in cases of patients presenting with acute abdomen.

In our cases, shunt assembly was removed through incision near chamber, except in case where shunt tube was coming through deep inguinal ring where shunt tube was reposited back in peritoneal cavity and inguinal herniotomy was done. In the oral or anal extrusion it is better to remove tube from anal or oral route, contaminated tube should not be allowed to be in contact with the peritoneum or the shunt tract ${ }^{20}$. This is done to decrease the theoretical risk of infection as peritoneal end was exposed to atmosphere and contaminated gut. Abdominal examination was normal in all our cases. CSF study was also normal. I/V antibiotics were given in all patients and patients were kept nil per orally for 3-4 days. VP shunt was re-inserted on opposite side either immediately or after 3-4 weeks depending upon CSF culture. In the meantime patient was managed by mannitol. Close follow up of 6-18 months was uneventful in all our cases.

\section{Conclusion}

Abnormal exstrusion of peritoneal end of shunt is rare but serious complication of VP shunt surgery. Clinical presentations include visible exstruded shunt tube through abnormal opening, fever, meningitis and abdominal infection. Management includes shunt removal, I/V antibiotics and shunt revision on opposite side/ ETV. Complications of abnormal shunt exstrusion are difficult to avoid, but close follow up of patients with VP shunt surgery helps timely intervention and prevents morbidity and mortality. 


\section{References}

1. Lifshutz JI, Jonson W.D. History of hydrocephalus and its treatments. Neurosurg. Focus. 2001;11(2):E1.

2. Akyuz M, Ucar T, Goksu E. A thoracic complication of ventriculoperitoneal shunt: symptomatic hydrothorax from intrathoracic migration of a ventriculoperitoneal shunt catheter. Br J Neurosurg. 2004;18(2):171-3.

3. Imamura $\mathrm{H}$, Nomura $\mathrm{M}$. Migration of ventriculoperitoneal shunt into the heart- case report. Neurol Med Chir(Tokyo).2002;42:181-3.

4. Eser O, Dogru O, Aslan A et al. Umbilical perforation: an unusual complication of a ventriculo-peritoneal shunt. Childs Nerv Syst. 2006;22:1509-10.

5. Zhou F, Chen G, Yhang J. Bowel perforation secondary to ventriculoperitoneal shunt: case report and clinical analysis. J Int Med Res. 2007;35:926-9.

6. Ramana Murthy KV, Jayaram Reddy S, Prasad DV. Perforation of the distal end of the ventriculoperitoneal shunt into the bladder with calculus formation. Pediatr Neurosurg. 2009;45(1):535.

7. De Aquino HB, Carelli EF, Borges Neto AG et al. Non-functional abdominal complications of the distal catheter on the treatment of hydrocephalus: an inflammatory hypothesis? Experience with six cases. Childs Nerv Syst. 2006;22(10):1225-30.

8. Borkar SA, Satyarthee GD, Khan RN, Sharma BS, Mahapatra AK. Spontaneous extrusion of migrated ventriculoperitoneal shunt catheter through chest wall: A case report. Turkish Neurosurgery. 2008;18(1):95-98.

9. Bryant MS, Bremer AM: Abdominal complications of ventriculoperitoneal shunts. Case reports and review of literature. Am Surg. 1988;54:50-5.

10. Martinez Hernández-Magro P, Barrera Román $C$, Villanueva Sáenz E et al. Colonic perforation as a complication of ventriculoperitoneal shunt: A case report. Tech Coloproctol 2006;10:353-5.

11. Vinchon $M$, Baroncini $M$, Laurent $T$ et al. Bowel perforation caused by peritoneal shunt catheter: Diagnosis and treatment. Neurosurgery 2006;58 Soppl 1: ONS 76-82; discussion ONS 76-82.

12. Surchev J, Georgiev K, Enchev Y et al. Extremely rare complications in cerebrospinal fluid shunt operations. J Neurosurg Sci. 2002;46:100-2.

13. Guillen A, Costa J M, Castello I et al. Unusual abdominal complications of ventriculoperitoneal shunt. Neurocirugia(A stur).2002;13:401-4.

14. Patel $C D$, Matloub $H$. Vaginal perforation as a complication of ventriculoperitoneal shunt. J Neurosurg.1973;38:711-2.

15. Ozveren MF, Kazez A, Cetin $\mathrm{H}$ et al. Migration of the abdominal catheter of a V P Shunt into scrotum: case report. Neurol Med Chir(Tokyo). 1999;39:313-5.

16. Sathyanarayana $S$, Wylen $E$, Baskaya $M$ et al. Spontaneous bowel perforation after ventriculoperitoneal shunt surgery: case report and a review of 45 cases. Surg Neurol. 2000;54:388-96.

17. Berhouma $M$, Messerer $M$, Houissa $S$ et al. Transoral protrusion of a peritoneal catheter: a rare complication of ventriculoperitoneal shunt. Pediatr. Neurosurg. 2008;44(2):169-71.

18. Thipphavong S, Kellenberger CJ, Rutka JT et al. Hepatic and colonic perforation by an abandoned ventriculoperitoneal shunt. Pediatr. Radiol. 2004;34:750-2.

19. Digray NC, Thappa DR, Arora M et al. Silent bowel perforation and transoral prolapse of a ventriculoperitoneal shunt. Pediatr. Surg. Int.2000;16:1-2;94-5.

20. Agarwal M, Adhana R, Namdev H, Yadav YR, Agrawal T. Transoral extrusion of the ventriculoperitoneal shunt: A case report and review of literature. J Pediatr Neurosci. 2011;6(2):149-151.

\section{How to cite this article?}

Kundal VK, Gajdhar M, Sharma C, Agrawal D, Kundal R. Wandering Distal End of Ventriculo-Peritoneal Shunt: Our Experience with Five Cases and Review of Literature. J Nepal Paediatr Soc 2012;32(3):266-269. 